\title{
Motivação de Viagem: uma problematização a partir dos pressupostos teóricos da análise do discurso pecheutiana
}

Maicon Gularte Moreira Luciene Jung de Campos ${ }^{\mathrm{b}}$

\section{Resumo}

Este trabalho se propõe a oferecer uma contribuição da análise do discurso para os estudos no campo do turismo. Reconhecendo a condição plural e contraditória da produção do conhecimento neste campo do saber, buscamos problematizar o modo como a motivação de viagem é produzida como própria do sujeito. Dessa forma, filiados ao dispositivo teóricometodológico da análise do discurso proposta por Michel Pêcheux, apresentamos o sujeito do inconsciente como sendo aquele que se desloca, pois é da ordem do desejo. Com isso, posicionamos a motivação de viagem em oposição ao deslocamento do sujeito desejante. A motivação de viagem, apresentada como o teatro da consciência, é um efeito ideológico produzido pela interpelação do sujeito como turista, cujas evidências de si e dos sentidos servem para controlar, censurar e cercear o próprio desejo do sujeito. Essa produção ideológica está ligada à realização da ideologia dominante no interior do turismo, apresentado como aparelho ideológico de Estado, responsável pela reprodução das relações de produção, que são as relações de exploração capitalistas, nas quais o desejo dos sujeitos não possui lugar.

Palavras-chave: Turismo; Análise do discurso; Motivação de viagem; Deslocamento; Ideologia.

\section{Abstract}

Travel Motivation: a problematization from the theoretical assumptions of pecheutian discourse analysis

This work offers a contribution for the discourse analysis in the field of tourism. Recognizing the diverse and contradictory conditions of the academic production in this field of knowledge, we aim to question the way of a travel motivation is produced as belonging to the subject. Therefore, affiliated to the theorical-methodological dipositive of discourse analysis proposed by Michel Pêcheux, we present the subject of the unconscious as the one who dislocates, because it is of the order of desire. That said, we place the travel's motivation in opposition to the displacement of the desiring subject. The travel motivation, which is shown as the theatre of the consciousness, is an ideological effect produced by the interpellation of the subject as tourist, whose evidences of itself and meanings are used to control, to censor, and to curtail the subject's desire. This ideological production is related to the fulfillment of the dominant ideology within the tourism, performed as an Ideological State apparatuses, responsible for the reproduction of the production relations, that are the capitalist exploitation relations, in which the subject's desire has no place.

Keywords: Tourism; Discourse analysis; Travel motivation; Displacement; Ideology.

a. Doutorando em Turismo e Hospitalidade da Universidade de Caxias do Sul (UCS). Mestre em Turismo pela UCS. Caxias do Sul, Rio Grande do Sul, Brasil. E-mail: maicongmoreira@gmail.com

b. Doutora em Estudos da Linguagem: Teorias do Texto e do Discurso pela Universidade Federal do Rio Grande do Sul (UFRGS). Docente do programa de Pós-graduação em Turismo e Hospitalidade da UCS. Caxias do Sul, Rio Grande do Sul, Brasil. E-mail: ljungdecampos@gmail.com 


\section{Resumen}

Motivación de Viaje: una problematización desde los presupuestos teóricos de la análisis del discurso pecheutiana

Este trabajo se propone a ofertar una contribución del análisis del discurso para los estudios en el campo del turismo. Reconociendo la condición plural y contradictoria de la producción del conocimiento en este campo del saber, buscamos problematizar el modo como la motivación de viaje es producida como propia del sujeto. De esa forma, afiliados al dispositivo teórico-metodológico del análisis del discurso propuesta por Michel Pêcheux, presentamos el sujeto del inconsciente como siendo aquel que se desplaza, pues es de la orden del deseo. Con eso, posicionamos la motivación de viaje en oposición al desplazamiento del sujeto desejante. La motivación de viaje presentada como el teatro de la conciencia, es un efecto ideológico producido por la interpelación del sujeto como turista, cuyas evidencias de sí y de los sentidos, sirven para controlar, censurar y cercear el propio deseo del sujeto. Esa producción ideológica está conectada a la realización de la ideología dominante en el interior del turismo, presentado como aparato ideológico de Estado, responsable por la reproducción de las relaciones de producción, que son las relaciones de explotación capitalistas, en las cuales el deseo de los sujetos no posee lugar. Palabras clave: Turismo; Análisis del discurso; Motivación de viaje; Desplazamiento; Ideología.

\section{REFLEXÕES INTRODUTÓRIAS}

0 turismo, em razão de sua condição multifacetada, é um campo de estudos multidisciplinar, passível de ser olhado a partir de diferentes lentes teóricas. Alguns pesquisadores consideram, inclusive, a possibilidade de situá-lo em uma dimensão transdisciplinar, ainda que seja (re)conhecida a hegemonia de algumas disciplinas sobre as demais. Essa condição, não entendida como desfavorável, tem imposto aos estudiosos do turismo certa dificuldade naquilo que se refere à construção conceitual do campo, tida como necessária para o delineamento de um quadro epistemológico. É possível que esses delineamentos (nunca) sejam alcançados, mas talvez nem devessem ser ambicionados - ou sim. Refletir, contudo, sobre e por meio dessa mise-en-scène é imperativo da posição que ocupamos enquanto pesquisadores.

Poderíamos pensar que nossa riqueza enquanto campo de estudos é esta: uma grandiosa colcha de retalhos elaborados com fios de diferentes materiais, bordados, texturas e cores. Assim nos caberia o árduo trabalho da análise, da problematização e da transformação dos processos pelos quais o turismo vai sendo tecido. É possível pensar em cada pedaço, fio e bordado desse tecido, a partir das diferentes mãos teóricas que o produzem, nos diferentes períodos históricos e sob diferentes paradigmas. Negar essa condição é negar a construção do conhecimento, sobretudo no campo do turismo. É recorrer a uma empobrecida reprodução do não pensamento ou do pensamento cínico (Laureano, 2015). É assumir a possibilidade de existência de uma razão homogênea, sólida e transparente capaz de nos dar o poder de responder a todos os enigmas.

É preciso, no entanto, reconhecer os esforços até aqui empreendidos com maior ou menor grau de aceitação. Nenhum trabalho, por mais astuto que seja, é produzido sem um referencial que lhe dê suporte. E é exatamente essa a crítica que propomos nesta introdução. Na intenção de compreender e guiar o 
deslocamento humano, acabamos guiados pelo sistema econômico do qual somos aparelho. E, mesmo tendo despertado em alguma medida para seus efeitos destrutivos, seguimos tentando racionalizá-lo e torná-lo palatável sob a premissa utilitarista da maximização dos efeitos positivos e minimização dos efeitos negativos. Necessitamos pensar como e de que somos constituídos.

Não é preciso grande esforço para perceber o que está sendo dito aqui. Como exemplo podemos retomar Santos Filho (2005) quando este já identificava, em seu livro Ontologia do turismo, que as bases sobre as quais o turismo se erguia eram uma reprodução da realidade fora da materialidade. Segundo ele, os conceitos de empreendedorismo e de sustentabilidade, por exemplo, mascaram as condições sob as quais nosso sistema econômico existe. Não há capitalismo sem precarização do trabalho, assim como não há capitalismo sem danos ao meio ambiente.

A contradição da produção do conhecimento no turismo consistiu, assim, por repetidas vezes, em ignorar a profundidade e o contexto das contribuições conceituais trazidas por referenciais de outros campos. Ao mesmo tempo, tais conceitos eram moldados, adaptados e transformados a serviço do mesmo sistema que permitia ignorá-los. Em nosso campo predominaram, inicialmente, as abordagens econômicas, contextualizadas em benefício do próprio sistema econômico vigente. E, por mais que outras disciplinas tenham sido aproximadas ao campo no decorrer de seu desenvolvimento teórico, a dimensão econômica possuía - e ainda possui - notório domínio. Segundo Pêcheux (2014), essa é uma caraterística própria das teorias da ideologia burguesa, que não somente faz com "que a distinção entre ciência e não-ciência seja encoberta" (p. 69), como sobretudo busca "esquecer a existência das disciplinas científicas historicamente constituídas" (p. 69) e visa "o ocultamento do registro político" (p. 111).

A ideologia burguesa, como a forma mais completamente desenvolvida, instrui-nos não apenas acerca do funcionamento da instância ideológica em geral, mas também sobre as formas históricas que a precederam. Todavia, não se devem projetar as formas burguesas da interpelação sobre as formas anteriores. Não é evidente, por exemplo, que a interpelação consiste sempre em aplicar sobre o próprio sujeito a sua determinação. A autonomia do sujeito como "representação da relação imaginária" é, de fato, estritamente ligada à aparição e à extensão da ideologia jurídico-política burguesa. (Pêcheux \& Fuchs, 1975/2014, p. 162)

A contradição, assim, não se coloca como lugar de transformação, destituindo a dialética como motor de transformação social (Laureano, 2015), pois "enquanto o sujeito reconhece a produção como fundamento histórico e material da sociedade, também é capaz de gozar do fetiche, do caráter ideológico do movimento de expansão do capital" (Laureano, 2015, p. 475), ou seja, do seu processo de produção/reprodução/transformação. Por isso, reconhecendo nossa condição falha, equívoca e contraditória enquanto mãos que tecem o turismo, pretende-se situar este trabalho a partir da interface de três campos teóricos: a psicanálise, o materialismo histórico e a linguística. Esses três campos teóricos foram utilizados no final da década de 1960 pelo filósofo francês Michel Pêcheux, na proposição do dispositivo teórico-metodológico da análise do discurso (AD). 
Por meio da AD, tem-se buscado enxergar o turismo de forma articulada. Essa interface possibilitará expor algumas reflexões que têm sido realizadas no âmbito de nossos estudos. Mais precisamente, queremos pensar uma possibilidade de aproximação entre o deslocamento - pensado por nós neste trabalho como o objeto do turismo -, o sujeito do inconsciente - objeto da psicanálise -, e o conceito de ideologia - trazido do materialismo histórico. Neste trabalho, iremos realizar essa aproximação colocando em questão os motivos pelos quais as pessoas viajam. Nosso objetivo, com este texto, é indagar como os motivos das viagens se tornam motivos, como são produzidos. Assim, apresentamos o deslocamento não apenas como espacial e temporal, mas como um ato histórico e ideológico performado por um sujeito que deseja e, portanto, (r)existe.

Dito de outra forma, a proposta deste texto é problematizar a produção da motivação de viagem como algo próprio ao sujeito, já que para isso precisaríamos admitir um sujeito centrado e da ordem da razão, um sujeito capaz do pleno controle de sua própria consciência e sobre o ato de deslocamento. Este é um ponto central e que deve ser levado em consideração na leitura deste trabalho. Durante nossa exposição, a motivação será apresentada como um efeito ideológico do "teatro da consciência". Ao contrário do sujeito da motivação, o sujeito de que trataremos é o sujeito do desejo em torno de um gozo impossível. Motivação e deslocamento, aqui, serão expostos em franca oposição.

Para isso, necessitamos num primeiro momento apresentar o conceito e o funcionamento do inconsciente freudiano, no qual o deslocamento psíquico acontece. Em seguida, vamos relacioná-lo aos modos de interpelação do sujeito do inconsciente pela ideologia. E, por fim, exporemos os modos de produção dos sentidos acerca da motivação de viagem, retomando brevemente as construções realizadas no turismo a partir da psicologia cognitivo-comportamental e da sociologia para, posteriormente, estabelecer seu contraponto no âmbito de nossas análises.

\section{O SUjeito do inconsciente é Aquele Que Se desloca}

Para apresentar o inconsciente, em sua obra inicial, Sigmund Freud procura identificar as formas e os modos como esse inconsciente se dá a ver e se manifesta nos sujeitos. Para isso, ele utiliza as análises de seus pacientes, da arte e a análise de si mesmo, como um modo de entender suas manifestações. Por esse motivo, recorremos aos estudos dos textos $A$ interpretação dos sonhos, Psicopatologia da vida cotidiana e Os chistes e sua relação com o inconsciente, nos quais Freud (1900/1996, 1901/1996, 1905/1996) identifica em sonhos, atos falhos, esquecimentos, equívocos na ação, erros, chistes etc., as manifestações pelas quais o inconsciente aparece. A partir delas, Freud começa a estabelecer algumas regras de funcionamento do inconsciente.

Ao acompanhar a incursão freudiana sobre o inconsciente e esse funcionamento, supomos que o inconsciente não é um conceito pronto ou dado, mas que se mostra a partir do sujeito e, portanto, existe quando o sujeito falha, tropeça, e/ou quando tudo aquilo que o sujeito não controla surge, emerge, ricocheteia em sua superfície. Conforme propõe a teoria psicanalítica, o sujeito falha porque é constituído por uma falta primordial que o faz desejar, e o momento em que a falta se instala é quando o inconsciente se estrutura. 
Essa falta significa que, para se inscrever no campo da linguagem, o sujeito precisou abrir mão de sua condição de completude primordial em relação à sua mãe, na qual nada lhe faltava. Essa falta é, consequentemente, aquilo que causa o desejo, mas diferenciando-se de uma necessidade. Esse desejo é o desejo de completude, ou seja, do (re)encontro com a mãe idealizada. Portanto, o objeto do desejo, ao mesmo tempo em que se esquiva e permanece oculto, porque não pode ser (re)encontrado, remete à própria causa do desejo (Lacan, 19601961/1992).

$\mathrm{Na}$ impossibilidade desse (re)encontro, o sujeito irá destinar suas pulsões para objetos que lhe demandem um baixo investimento de energia, ou seja, para outros objetos que lhe permitam a satisfação parcial do desejo, em detrimento daqueles objetos de alto investimento, ou seja, que lhe causem maior sofrimento pelo desejo primordial que não pode ser satisfeito (Freud, 1901/1996). A esse processo, em psicanálise, dá-se o nome de deslocamento (Freud, 1905/1996), que aqui chamaremos de deslocamento psíquico. Isso de forma alguma quer dizer que as experiências de deslocamento psíquico não podem gerar sofrimento, mas apenas que se apresentam como uma possibilidade de gratificação parcial de um desejo inconsciente.

O deslocamento psíquico é, portanto, o processo no qual conteúdos inconscientes podem se gratificar, manifestar, aparecer, gozar, ainda que parcialmente. Isso será entendido por Lacan (1998, p. 515) como "o transporte da significação que a metonímia demonstra e que, desde seu aparecimento em Freud, é apresentado como o meio mais adequado do inconsciente para despistar a censura". Isso significa que o deslocamento psíquico é o transporte da significação do desejo primordial para um objeto de desejo metonímico (Lacan, 19571958/1999) pelo qual o sujeito possa alcançar alguma gratificação pulsional, para além daquilo que regula/censura o seu desejo. Aqui destaca-se a relação de poder existente entre censura, ideologia e desejo. Ou seja, o deslocamento psíquico é uma forma de resistência à interpelação do sujeito do inconsciente, por meio da qual o desejo é controlado.

Nesse sentido, o desejo inconsciente de reencontro com o objeto perdido possui, diretamente, relação com a ideologia e com a linguagem, pois a ideologia é responsável por regular/censurar as possibilidades de simbolizarmos nosso desejo com a linguagem e, com isso, de nos apropriarmos dos objetos de gratificação parcial do desejo para dizer onde podemos gozar. Esse gozar, no âmbito da interpretação psicanalítica, pode significar muitas possibilidades de gratificação do desejo desse sujeito interpelado, como, por exemplo, viajar, consumir bens e serviços, quebrar o cotidiano, se libertar, restaurar as energias etc.

O desejo, portanto, é interpretado aqui como aquilo que move o sujeito em direção a algo, a um objeto que marca esse desejo, mas que se diferencia de uma necessidade. Esta última é da ordem da satisfação gerada por objetos correspondentes como, por exemplo, o alimento corresponde às necessidades nutricionais do corpo. 0 desejo é o desejo de sua realização, da ordem do recalcado, portanto, do não sabido, e só pode ser gratificado parcialmente através da realização alucinatória desse desejo, como nos sonhos, ou pelo seu desdobramento na fantasia (Freud, 1900/1996).

Nesse eterno recortar-se e mover-se, o sujeito não se desloca só fisicamente no tempo e no espaço, mas se desloca fisicamente no tempo e no espaço em razão de um processo de deslocamento psíquico, um processo inconsciente 
que o faz mover-se em direção a algo, mesmo sem saber o quê. Como registrou Lacan (19601961/1992, p. 126), “o amor é dar o que não se tem”, possivelmente a alguém que não o quer.

É, pois, no campo discursivo regulado por formações ideológicas que são travadas as batalhas de interpelação dos sujeitos, o jogo de forças entre censura e desejo no qual são autorizados alguns objetos de desejo em detrimento de outros. São aqui autorizados alguns sentidos a respeito da satisfação do desejo que permitam aos sujeitos experimentar momentos de gozo, ao mesmo tempo que viabilizem a reprodução das condições de produção capitalistas.

\section{IDEOLOGIA E AS CONDIÇÕES DE PRODUÇÃO DO DESLOCAMENTO}

Nesse encadeamento reflexivo, é imprescindível expormos o modo como tratamos o conceito da reprodução das condições de produção, ou seja, de que reprodução e de quais condições de produção falamos. Louis Althusser (2003), em seu trabalho intitulado Aparelhos ideológicos de Estado, realiza uma (re)leitura sobre parte da obra marxista e também faz suas considerações e proposições a respeito de uma teoria das ideologias em geral. 0 autor parte de duas premissas: não há produção sem a reprodução das condições de produção; e "toda formação social é resultado de um modo de produção dominante" (Althusser, 2003, p. 54). Logo, para poder produzir, toda formação social deve reproduzir as forças produtivas (força de trabalho e meios de produção) e as relações de produção existentes que, na sociedade de classes, são as relações entre a força de trabalho e os donos dos meios de produção (Althusser, 2003).

A reprodução da força de trabalho ocorre, em parte, à maneira do seu meio material de se reproduzir: o salário. Além disso, a força de trabalho deve viabilizar sua utilização no processo de produção por meio da reprodução de sua qualificação. Ao contrário dos sistemas produtivos anteriores ao capitalismo, a qualificação dessa força de produção não mais ocorre na própria produção, mas fora dela.

A reprodução da força de trabalho não exige somente uma reprodução de sua qualificação mas ao mesmo tempo uma reprodução de sua submissão às normas da ordem vigente, isto é, uma reprodução da submissão dos operários à ideologia dominante por parte dos operários e uma reprodução da capacidade de perfeito domínio da ideologia dominante por parte dos agentes da exploração e repressão, de modo a que eles assegure também "pela palavra" o predomínio da classe dominante. (Althusser, 2003, p. 58)

A reprodução das forças produtivas é, portanto, a restauração dessas forças de modo que seja possível seu uso. Nessa cena apresenta-se, ainda, o conceito de ideologia. Conforme o mesmo autor, "a ideologia é uma 'representação' da relação imaginária dos indivíduos com suas condições reais de existência" (Althusser, 2003, p. 85). Cabe destacar que a ideologia não é a representação real do sistema que opera sobre a vida das pessoas, mas a relação imaginária dessas pessoas com as relações reais sob as quais existem.

Nesse sentido, devido à existência material da ideologia, Althusser (2003, p. 93) vai entender que "só há prática através de e sob uma ideologia", bem como "só 
há ideologia pelo sujeito e para o sujeito", pois os indivíduos já são sempre sujeitos, uma vez que já são sempre interpelados por uma ideologia, mesmo antes de seu nascimento. "A ideologia interpela os indivíduos enquanto sujeitos" (Althusser, 2003, p. 93).

É preciso que assim seja, para que as coisas sejam o que devem ...; para que a reprodução das relações de produção seja, nos processos de produção e de circulação, assegurada diariamente, na "consciência", ou seja, no comportamento dos indivíduos-sujeitos, ocupantes dos postos que a divisão social-técnica do trabalho lhes designa na produção, na exploração, na repressão, na ideologização, na prática científica, etc. (Althusser, 2003, p. 104)

Há, portanto, por parte da ideologia uma necessidade de esconder, camuflar e ocultar todo esse processo de interpelação do indivíduo enquanto sujeito submisso a uma estrutura especular duplicada, "subjugado, submetido a uma autoridade superior, desprovido de liberdade, a não ser a de livremente aceitar a sua submissão" (Althusser, 2003, p. 104). Igualmente, há por parte da AD pecheuatiana uma necessidade de questionar o modo como ocorre esse processo através do qual se origina o sujeito do discurso, que é o sujeito do inconsciente interpelado pela ideologia para que possa dizer e ser dito. Conforme Pêcheux:

Se é verdade que a ideologia "recruta" sujeitos entre os indivíduos ... e que ela os recruta a todos, é preciso, então, compreender ... de que modo todos os indivíduos recebem como evidente o sentido do que ouvem e dizem, lêem ou escrevem (do que eles querem e do que se quer lhes dizer), enquanto "sujeitos-falantes": compreender realmente isso é o único meio de evitar repetir, sob a forma de uma análise teórica, o "efeito Münchhausen", colocando o sujeito como origem do sujeito, isto é, no caso do que estamos tratando, colocando o sujeito do discurso como origem do sujeito do discurso. (Pêcheux, 2014, p. 144, grifos do autor)

Os processos descritos até aqui são possibilitados porque o sujeito de que tratamos é o sujeito do inconsciente interpelado pela ideologia. Resta compreender de que modo a ideologia opera sobre o inconsciente para que o sujeito seja interpelado a se deslocar fisicamente. Para estabelecer essa ligação, entre ideologia e inconsciente, Pêcheux (2014, p. 139, grifos do autor) observa que ambas estruturas dissimulam "sua própria existência no interior mesmo do seu funcionamento, produzindo um tecido de evidências 'subjetivas', devendo entender-se este último adjetivo não como 'que afetam o sujeito', mas 'nas quais se constitui o sujeito'". Para ele, é nesse ponto de evidência que inicia o delineamento de uma teoria materialista do discurso, comparando a evidência da existência do sujeito como origem ou causa de si com a evidência da transparência da linguagem, que designa que o dito só poderia ser dito e significado de uma forma. Esse jogo de evidências é chamado de efeito ideológico (Pêcheux, 2014), em referência ao conceito já proposto por Althusser (2003), mas ampliado por Pêcheux (2014).

Nessa relação entre evidências - a evidência do sujeito e a evidência do sentido - ou, como diz Pêcheux (2014, p. 140, grifos do autor), na "determinação pela qual a questão da constituição do sentido se junta à da constituição do sujeito", é onde se situa a interpelação. É por meio da interpelação, concebida como uma 
ilustração do "teatro da consciência" (Pêcheux, 2014, p. 140), que podemos retomar a noção de motivação e apresentá-la como um efeito ideológico da interpelação do sujeito. Ao dizer isso, estamos localizando a produção da motivação fora do sujeito, ou seja, na ideologia. Para apreender essa afirmação, precisamos retomar duas considerações já realizadas: a ideologia é constitutiva do sujeito e o sujeito constitutivo da ideologia; e a ideologia e o inconsciente funcionam ocultando suas existências. Dessa forma, "o que na realidade ocorre na ideologia parece ocorrer fora dela" (Althusser, 2003, p. 97).

Isso implica que o sujeito irá se achar fora da ideologia, ainda que esteja dentro dela, levando-se a acreditar na motivação como um ato de sua própria vontade, mas que na realidade é uma forma de controle externo de seu desejo. A motivação será apresentada por Dejours (2012) como essa tentativa de controle do sujeito, no sentido de direcionar o seu comportamento para a realização de tarefas determinadas. A motivação é, portanto, um registro imaginário que dissimula a impossibilidade da realização do desejo, uma ilustração do teatro da consciência, uma ilusão. É um sentido produzido em torno de um objeto de desejo - a viagem - como possibilidade de satisfação do desejo inconsciente que jamais se realizará. Essa é, precisamente, a dialética do funcionamento da interpelação ideológica dos indivíduos em sujeitos, pois se apresenta como uma estrutura “'concreta' o suficiente para que possa ser reconhecida e abstrata o suficiente para que possa ser pensável e pensada" (Althusser, 2003, p. 96).

Em consequência, a interpelação assume uma importante função no contexto da reprodução das relações de produção. Ela será a viabilizadora da relação entre o aparelho (repressivo) de Estado e os aparelhos ideológicos de Estado (AIE), ou ainda, do 'vínculo entre o 'sujeito de direito' (aquele que entra em relação contratual com outros sujeitos de direito; seus iguais) e o sujeito ideológico (aquele que diz ao falar de si mesmo: 'Sou eu!')" (Pêcheux, 2014, p. 140, grifos do autor). Dessa forma, a evidência de existência do sujeito, de existência de sua identidade, torna-se o resultado dessa identificação/interpelação. É nesse sentido que opera o teatro da consciência de que fala Pêcheux (2014, p. 140, grifos do autor), como o lugar em que "se fala do sujeito, que se fala ao sujeito, antes de que o sujeito possa dizer: 'Eu falo'”.

É nesse lugar que buscamos apreender o sujeito de que falamos, o lugar em que ele enuncia ao ser enunciado, em que ele pensa ao ser pensado, em que ele fala ao ser falado, em que ele significa ao ser significado. No teatro da consciência é onde se exibe, espetacularmente, o inconsciente do sujeito estruturado como linguagem (Lacan, 1964/1996), uma linguagem que preexiste ao sujeito (Lacan, 1998), tal como a ideologia (Althusser, 2003).

Retomando do início, expusemos que, para produzir, além da reprodução das forças produtivas, toda a formação social deve reproduzir as relações de produção. Althusser (2003) propõe que essa reprodução das relações de produção é garantida por uma das partes que constituem o modelo de sociedade proposto pela teoria marxista: a superestrutura (jurídicopolítica e ideológica). Dito de outro modo, a reprodução das relações de produção é garantida pelo exercício do poder do Estado ora através da repressão, ora através da ideologia, em níveis distintos, mas nunca dissociados um do outro (Althusser, 2003, p. 73).

Os aparelhos (repressivos) do Estado são instituições, em geral públicas, constituídas pelos representantes políticos das classes dominantes, detentoras 
do poder, como governo, administração, exército, polícia, tribunais, prisões etc. Buscam garantir pela força física (ou não) as condições políticas da reprodução das relações de exploração (Althusser, 2003). Já os AIE são instituições, públicas e/ou privadas, cujo funcionamento se dá, principalmente, para a e pela ideologia dominante, visando garantir a reprodução das relações de produção, asseguradas pelo exercício do poder repressivo do Estado (Althusser, 2003).

No contexto do que expomos até aqui, parece-nos plausível sugerir que o turismo atua como um AIE, mesmo que ainda não tenhamos condições de localizá-lo na tipologia dos AIE proposta por Althusser (2003). Entendemos isso dessa forma porque o turismo atua como o reprodutor das relações de produção capitalistas, contraditoriamente, pela interpelação ideológica do sujeito como um turista, por meio do jogo de força existente na relação entre a ideologia e o inconsciente do sujeito desejante.

Acreditamos ter conseguido, assim, apresentar a motivação de viagem como uma produção ideológica ou, como já dito, um efeito ideológico da interpelação do sujeito em turista, pela reprodução das forças produtivas e, sobretudo, pela reprodução das relações de produção capitalistas pelo turismo, enxergado como um aparelho ideológico de Estado. 0 sentido do deslocamento já está dado antes mesmo que o sujeito se desloque. Isso marca a impossibilidade de preenchimento do vazio do sujeito desejante, ao mesmo tempo que o faz desejar ou, no caso, deslocar-se. Acatamos o desejo do Outro, que nos convoca à experiência de um gozo que jamais será pleno, e nos deslocamos, psíquica e fisicamente.

\section{(IN)FLEXÕES DO/NO TURISMO}

Ao refletir sobre as contradições no campo das ciências sociais, Michel Pêcheux, sob o pseudônimo de Thomas Herbert (1995), diz que o objeto de determinado campo científico deve, num primeiro momento, ser construído de forma teórica e conceitual, para depois ser reproduzido. Logo, essa reprodução "não pode ser exercida senão na medida em que a transformação produtora do objeto já tenha ocorrido" (Henry, 1969/2014, p. 15), ou seja, a primeira fase deve ser destinada a "subverter o discurso ideológico natural 'dado'” (Herbert, 1995, p. 64). Assim, Herbert (1995) alerta que, quando a primeira etapa é tomada pela prática conceitualexperimental - o que geralmente ocorre nas ciências sociais -, é porque "o efeito de ruptura em relação à ideologia não havia sido produzido, e [por]que, consequentemente, a experimentação reproduzia esta afirmando sua realidade ilusória (efeito de realização do real)" (Herbert, 1995, p. 65). Com isso, a prática científica é transformada num desdobramento da prática técnica, como é o caso do que ocorreu no turismo.

Segundo Moesch (2000), grande parte da produção realizada no campo do turismo o concebe como um produto, pois pressupõe que ele é capaz de satisfazer necessidades humanas. Essa concepção, entendida tanto por Moesch quanto por nós como equivocada, abre brechas para que sejam interpretados da mesma forma bens de consumo e sujeitos (Moesch, 2000). Não se trata, aqui, de ignorar tais aspectos, mas, pelo contrário, de mostrar outras relações existentes, inclusive permeadas pelo campo da economia, sem que se coisifique o aspecto humano. Como diz Santos Filho (2005, p. 16) sobre o estudo do turismo, este "só será possível se entendermos as dimensões global, histórica e dialética". 
Em seu trabalho, Moesch (2000) destaca que os conceitos mais comuns se importavam em fazer uma relação do turismo com seus efeitos econômicos, deixando de lado a importância da teoria e/ou a preocupação metodológica do conhecimento do fenômeno. Isso se deu pelo fato de ter sido estudado, num primeiro momento, por economistas, cujos estudos baseavam-se em dados estatísticos, oferta e demanda, projetos etc. Essa concepção epistemológica empirista, aos poucos, foi sendo contestada, porém a reprodução teórica já havia se iniciado antes de sua produção. Não podemos esquecer que o turismo nasce, primeiro, como atividade econômica e só depois passa a ser objeto de estudos.

Assim, quando se fala em motivação de viagem, alguns bordões acabam vindo à mente imediatamente. Tomamos como exemplo, para expor o que pretendemos aqui, duas abordagens da motivação no turismo amplamente conhecidas e utilizadas. A primeira, uma das pioneiras, é a do sociólogo escocês Graham M. S. Dann $(1977,1981)$. A segunda, as teses sobre motivação levantadas pelo economista suíço Jost Krippendorf (2009).

Em busca de responder à questão “o que faz os turistas viajarem?", Dann (1977) descobriu que a distinção entre os fatores push - fatores internos que predispõem o turista à viagem- e pull - fatores externos que atraem o turista à viagem - era aceita entre os estudiosos do tema, e que, entre eles, havia uma preferência pela utilização de fatores pull para explicar por que os turistas viajavam. Ele decide, então, trabalhar em torno dos fatores push, presumindo que são temporalmente anteriores, pois ainda que haja uma atração do turista para um determinado local, sua decisão real seria dada a partir de suas necessidades anteriores de viajar.

Com isso, propôs ir além da descrição de fatores externos e caminhar em direção à compreensão dos níveis fisiológicos e psicológicos envolvidos nos fatores push, a partir do conceito durkheimiano de anomia e do conceito de "ego-enhancement" (Ludberg, 1971, citado por Dann, 1977, p. 186), que podemos traduzir como melhoria, aprimoramento ou aumento de ego. Assim, para Dann (1977), a anomia social seria responsável pela necessidade do sujeito de se afastar de seu contexto de vida, e o fator ego-enhancement seria responsável pela necessidade do sujeito de ser reconhecido, de buscar uma diferenciação, em termos de status, por meio de suas viagens. Dann (1981) estava tão convencido sobre sua teoria que considerou, inclusive, que os fatores push não eram apenas anteriores aos fatores pull, mas que sem os fatores push o deslocamento turístico não ocorreria.

Com a aproximação da psicologia cognitivo-comportamental e da sociologia, Dann inaugura no turismo uma série de abordagens produzidas ao longo das décadas por diferentes autores (Crompton, 1979; Gnoth, 1997). Eles irão desdobrar a motivação de viagem sobre os fatores push e pull, alterando seu entendimento em maior ou menor escala, mas jamais se afastando de suas premissas básicas: há algo anterior que impõe ao sujeito uma necessidade de viajar, e há algo externo ao sujeito que o atrai à viagem em função de sua necessidade.

Nosso contraponto em relação a essas abordagens reside no fato de que, diferentemente do sujeito da AD pecheutiana apresentado aqui, para Dann (1977) e seus seguidores, o processo de motivação de viagem, quer seja interior ou exterior ao sujeito, é totalmente consciente, ou seja, o sujeito de que tratam é da ordem da razão, aquele que sabe o que o quer, consciente de si e do mundo em que vive. Ora, se nada fosse opaco a esse sujeito, tudo lhe seria transparente, e nada lhe barraria o desejo. Dialeticamente, poderíamos até supor que esse 
sujeito tampouco desejaria, pois tudo estaria ao seu alcance. Sujeito da consciência e fatores externos de motivação são dialeticamente antagonistas. 0 sujeito da consciência não é o sujeito que se desloca no turismo.

Nesse sentido, é interessante perceber como a obra de Krippendorf (2009) carrega traços da teoria cognitivocomportamental e da teoria sociológica de Dann (1977) no que se refere às motivações de viagem, ainda que não seja possível afirmar tal influência direta. Ele apresenta teses sobre a motivação de viagem que podem esclarecer nossa argumentação. Em suma, Krippendorf (2009, p. 34) propõe que "o cotidiano só será suportável se pudermos escapar dele", fator push de anomia referida por Dann (1977). As viagens, para ele, têm a capacidade de "reconstituir, recriar o homem, curar e sustentar o corpo e a alma, proporcionar uma fonte de forças vitais e trazer um sentido à vida" (Krippendorf, 2009, p. 34), fator push de ego-enhancement também referido por Dann (1977). Ao mesmo tempo, o autor reconhece que a viagem "não é tanto o resultado de um impulso pessoal quanto à influência do meio social, que fornece a cada um suas normas existenciais" (Krippendorf, 2009, p. 36) e também que o mercado de viagens é um mercado de negócios, para o qual a "razão da viagem não tem importância. 0 que lhes interessa é que a viagem seja empreendida" (Krippendorf, 2009, p. 39).

Na contradição exposta, Krippendorf diz muito mais do que aquilo que escreve. 0 cotidiano, o trabalho e a vida atingiram níveis de exploração do ser humano adjetivados pelo autor como insuportáveis e degradantes, em razão de um sistema econômico que necessita reproduzir suas condições produtivas, que são condições de exploração, por meio do controle social. Para poder (re)produzir, não importam os reais anseios daqueles que viajam. Não há qualquer preocupação em aprofundar a discussão acerca da subjetividade humana, pois esta, vista dos bastidores do "teatro da consciência" (Pêcheux, 2014, p. 140), não interessa. No palco desse teatro, somos livres para viajar e viajamos para sermos livres, um paradoxo que expõe a contradição enunciada por Althusser (2003): devemos ser livres apenas para aceitar a nossa submissão, ou seja, viajar.

A lista composta por teses de motivações de viagem apresentadas por Krippendorf (2009), a partir do significado das viagens para os turistas, beira o senso comum. Segundo ele, viajar é descansar e refazer-se, compensar e integrar-se socialmente, fugir, comunicar-se, alargar o próprio horizonte, ser livre e independente, partir para a descoberta de si mesmo, ser feliz (Krippendorf, 2009). Essas teses apenas ratificam o quanto as condições de produção capitalistas se dão por via da exploração da força de trabalho, bem como do esfacelamento de toda e qualquer possibilidade de compreensão do aspecto humano.

Por fim, constata que a viagem é muito mais pelo "desejo de deixar alguma coisa do que pelo de ir para alguma coisa" (Krippendorf, 2009, p. 50). Dessa forma, a motivação surge como a possibilidade de controle do sujeito, que inconscientemente se afasta da impossibilidade de inscrição do seu desejo. Como já dissemos, o sentido do deslocamento já está dado antes mesmo que o sujeito se desloque, pois são as condições de produção do deslocamento, e não o deslocamento em si, que garantem o sentido da viagem.

Para buscar uma aproximação ao contexto em que o turismo se insere na reprodução das relações de produção, convocamos como texto orientador as contribuições de Santos Filho (2005), em seu livro Ontologia do turismo: estudos de suas causas primeiras. Em resumo, o autor sugere com o seu trabalho pensar o 
turismo em sua concepção histórica, desde o surgimento da mercadoria, quando surge o capital, e segundo o desenvolvimento dos modos de produção, ao contrário de pensá-lo a partir do surgimento do capitalismo.

Entendendo que as atividades de turismo ocorrem durante o tempo do não trabalho, Santos Filho (2005) desenvolve seu pensamento mostrando gradativamente que o trabalho vai se distanciando do não trabalho à medida que vai se tornando uma necessidade individual e não mais coletiva. Assim, ele mostra esse distanciamento progressivo através da evolução dos modos de produção. 0 auge desse processo ocorre no último modo de produção exposto pelo autor, o capitalismo, indicando a separação radical entre trabalho e não trabalho e a diferenciação do "lazer das obrigações profissionais" (Santos Filho, 2005, p. 37).

E, como nada pode obstruir a produção e acumulação de capital, o tempo de não trabalho também precisa reproduzir o modo de produção dominante. Logo, é nesse modo de produção "que a mercadoria assume a condução da vida e coisifica a relação humana ao máximo de sua exploração, mercantilizando e determinando o tempo dos homens" (Santos Filho, 2005, p. 37). Não apenas o tempo de trabalho seria tratado, pois, como mercadoria, mas o tempo de não trabalho também. 0 turismo possui, assim, em sua materialidade histórica, o embrião de seu funcionamento imbricado no jogo de forças entre a resistência do sujeito do inconsciente e a regulação da ideologia dominante sobre o tempo de não trabalho.

Esse é o movimento sobre o turismo que nossa reflexão tenta alcançar. 0 capitalismo "produz o fetichismo e/ou a falsificação da realidade" a partir da "retração entre a materialidade e o ideológico" (Santos Filho, 2005, p. 37), abrindo espaço para que essa forma de reprodução, além de organizar e determinar o tempo de não trabalho, venda o lúdico e produza formas de lazer que são "idiotizantes, despolitizantes e apelam para um descompromisso total com o cotidiano, uma vez que tratam da realidade fora da materialidade, descomprometendo o ser de sua existência histórica" (Santos Filho, 2005, p. 37). Isso ocorre pois é a fantasia a responsável por tamponar a impossibilidade de realização do desejo primordial, no qual apenas podemos desejar o desejo do Outro. A fantasia esconde "o fato de que o Outro, a ordem simbólica, se estrutura em torno de algo que não pode ser simbolizado, isto é, o real do gozo: através da fantasia o gozo é domesticado" (Žižek, 1992, p. 121)

Na barra da cortina que revela o palco do espetáculo apresentado por Debord, o turismo é bordado em toda a sua complexidade. É "resultado e projeto do modo de produção existente" (Debord, 1997, pp. 1415), porque nasce com o capital e a mercantilização do tempo livre e vai sendo (re)organizado, com vistas a ocultar a realização da ideologia de Estado, que é a ideologia da classe dominante, no contexto das relações de produção capitalistas, que são relações de exploração. O turismo "é a afirmação onipresente da escolha já feita na produção, e o consumo que decorre dessa escolha" (Debord, 1997, pp. 1415), visto que sua oferta, como já dissemos, antecipa o sentido da viagem para o sujeito, não permitindo que ele se inscreva como sujeito desejante, interessando-lhe apenas que a viagem seja empreendida.

Pelas relações estabelecidas, percebemos, assim, o turismo enquanto aparelho ideológico de Estado, responsável por garantir a reprodução das relações de produção. Ele se estruturou, como dito por Santos Filho (2005), antes do surgimento do sistema econômico capitalista, mas tem se (re)organizado desde então. 
Em que pese nossa proposição, isso ocorre com maior intensidade hoje, pois, de acordo com Ferrari (2011), uma das consequências psíquicas ocorridas na passagem da sociedade de produção para a sociedade de consumo é que os sujeitos passam a se identificar com tipos ideais, como o turista, por meio de um supereu imperativo do gozo, e não mais pela repressão.

E como já alertava Krippendorf (2009, p. 25), na década de 1980, todas as esferas da existência atual estão sujeitas a uma "economização", pois a economia reina em nossa sociedade. Ou, ainda, como disse Debord (1997, p. 30), "a economia transforma o mundo, mas o transforma apenas em mundo da economia". Logo, "o tempo que tem sua base na produção de mercadorias é ele próprio uma mercadoria consumível” (Debord, 1997, p. 104). 0 tempo consumível será usado, nesse sentido, como a matéria-prima de novos produtos, sobretudo daqueles que irão configurar a economia de serviços. Essas formas de mercadoria espetacular "só podem existir em função da penúria das realidades correspondentes" (Debord, 1997, p. 105).

O turismo, circulação humana considerada como consumo, resume-se fundamentalmente no lazer de ir ver o que se tornou banal. 0 planejamento econômico da frequência de lugares diferentes já é em si mesmo a garantia da equivalência. A mesma modernização que retirou da viagem o tempo, lhe retirou também a realidade do espaço. (Debord, 1997, p. 112, grifo do autor)

Resumindo, em razão das condições de produção do sistema capitalista, que são condições de exploração, o sujeito é interpelado a refazer-se, compensar-se, fugir, ser livre, independente e feliz. Logo, o interesse em aferir e monitorar a motivação de viagem se apresenta como um meio de controlar o gozo do sujeito, a partir de consultas/indagações sobre suas fantasias. A garantia de assujeitamento do sujeito e da domesticação do seu gozo são necessárias para reproduzir não apenas as forças produtivas, mas sobretudo as relações de produção. 0 turismo, enquanto aparelho ideológico de Estado, é responsável pela realização da ideologia dominante, que é a ideologia da classe dominante. Para isso, estrutura-se como um espetáculo no qual o teatro da consciência se apresenta, e a objetivação do sujeito é aplaudida de pé (Marx, 2017). 0 sujeito que se desloca não é aquele que sabe, mas sim aquele que não sabe o que quer.

\section{CONSIDERAÇÕES GERMINAIS}

O turismo, como apresentado ao longo deste texto, é muito mais o ato de afastamento do que um ato de busca. 0 sujeito se desloca psíquica e fisicamente na tentativa de reformular, de reapresentar e de gratificar, ainda que parcialmente, o desejo censurado. 0 deslocamento, em seu amplo sentido, é sobretudo um ato político e ideológico de resistência do sujeito e de insistência do desejo. Ao problematizar a motivação de viagem, indagando como ela se torna uma motivação, deparamos com a impossibilidade de o sujeito desejar. Logo, o deslocamento, antes de ocorrer no tempo e no espaço, ocorre no inconsciente do sujeito, que é desejante. 0 turismo passa a ser entendido como um fator de separação, tornando-se evidente o caráter contraditório pelo qual se constitui. 
Assim, propomos pensar o turismo a partir das disciplinas que o tecem. Apenas após essa retomada é possível que haja condições de elaborar, ou não, conceitos próprios que deem conta dos fenômenos observados por essas lentes teóricas. Um movimento dialético necessário, de encontro ao paradigma positivista que concebe uma ciência racional, cuja consciência homogênea, sólida e transparente comprova e afirma todas as respostas. Tudo vê. Se assim o fosse, nada nos restaria a saber, tudo estaria dado, à nossa disposição. Nós nos descobriríamos enfastiados e sem qualquer função enquanto pesquisadores.

Dessa forma, convidamos não apenas ao reconhecimento de nossa condição falha e contraditória na produção do conhecimento no campo do turismo, mas também a realizar um retorno ao funcionamento ideológico que deu base à estruturação desse saber. Com esse objetivo, desafiamo-nos pela indagação: como as motivações de viagem se tornam motivações de viagem? Ao realizar tal pergunta, acabamos sendo confrontados por diversas outras como, por exemplo, "a motivação de viagem é um conceito?” Optamos por não preencher essa questão com respostas, apenas ratificando que a motivação é da ordem da consciência, ou seja, da razão plena, homogênea e transparente. Ela pressupõe o viajante que sabe o que quer, que sabe para onde está indo e que sabe o que vai encontrar no destino.

A partir de nossa filiação ao campo teórico da análise do discurso proposta por Michel Pêcheux, assumimos que o sujeito do inconsciente é aquele que se desloca e o faz diante de um desejo primordial, cuja fantasia de um gozo pleno tampona a impossibilidade de sua realização. Com esse entendimento, posicionamos o deslocamento em oposição à motivação. 0 sujeito que se desloca é o sujeito do desejo. A motivação de viagem é o teatro da consciência, um efeito ideológico produzido pela interpelação do sujeito como turista, cuja evidência de si e a evidência dos sentidos servem para controlar, censurar e cercear o próprio desejo; onde o mercado visa oferecer ao viajante tudo aquilo que ele quer que o viajante queira. Nessa perspectiva, a noção de motivação de viagem trata de fazer o sujeito ocupar um lugar, na tentativa de preenchê-lo enquanto um ideal externo ideológico, que passa a ser internalizado pelo sujeito após interpelado em turista.

Essa produção ideológica está ligada à realização da ideologia dominante no interior do turismo, que apresentamos como aparelho ideológico de Estado. Ele, portanto, parte do conjunto complexo dos aparelhos de Estado, sendo responsável pela reprodução das relações de produção, que são as relações de exploração capitalistas, nas quais o desejo não possui lugar, apenas roteiro. Problematizar é, enfim, colocar questões, não as responder. É perturbar, instigar à produção de novos questionamentos. E, com isso, quisemos subsidiar e ampliar a discussão sobre o lugar do sujeito no turismo.

\section{REFERÊNCIAS}

Althusser, L. (2003). Aparelhos ideológicos de Estado: nota sobre os aparelhos ideológicos de Estado (AIE) (9aㅡ ed.). Rio de Janeiro, RJ: Edições Graal.

Crompton, J. L. (1979). Motivations for pleasure vacation. Annals of Tourism Research, 6(4), 408424. doi:10.1016/0160-7383(79)90004-5 
Dann, G. M. S. (1977). Anomie, ego-enhancement and tourism. Annals of Tourism Research, 4(4), 184-194. doi:10.1016/0160-7383(77)90037-8

Dann, G. M. S. (1981). Tourist motivation: an appraisal. Annals of Tourism Research, 8(2), 187-219. doi:10.1016/0160-7383(81)90082-7

Debord, G. (1997). A sociedade do espetáculo. Rio de Janeiro, RJ: Contraponto.

Dejours, C. (2012). A carga psíquica do trabalho. In C. Dejours, E. Abdoucheli, \& C. Jayet (Orgs.), Psicodinâmica do trabalho: contribuições da escola dejouriana à análise da relação prazer, sofrimento e trabalho (pp. 21-32). São Paulo, SP: Atlas.

Ferrari, C. M. M. (2011). 0 supereu imperativo do gozo nas viagens. Revista Hospitalidade, 8(2), 7190. Recuperado de: https://bit.ly/2Kt6lj4

Freud, S. (1996). A interpretação dos sonhos I. In S. Freud, Edição standard brasileira das obras psicológicas completas de Sigmund Freud (Vol. 4). Rio de Janeiro, RJ: Imago. (Trabalho original publicado em 1900)

Freud, S. (1996). Sobre a psicopatologia da vida cotidiana. In S. Freud, Edição standard brasileira das obras psicológicas completas de Sigmund Freud (Vol. 6). Rio de Janeiro, RJ: Imago. (Trabalho original publicado em 1901)

Freud, S. (1996). Os chistes e a sua relação com o inconsciente. In S. Freud, Edição standard brasileira das obras psicológicas completas de Sigmund Freud (Vol. 8). Rio de Janeiro, RJ: Imago. (Trabalho original publicado em 1905)

Gnoth, J. (1997). Tourism motivation and expectation formation. Annals of Tourism Research, 24(2), 283304. doi:10.1016/S0160-7383(97)80002-3

Henry, P. (2014). Os fundamentos teóricos da "análise automática do discurso" de Michel Pêcheux. In F. Gadet, \& T. Hak (Orgs.), Por uma análise automática do discurso: uma introdução à obra de Michel Pêcheux (9a ed., pp. 1138). Campinas, SP: Editora da Unicamp. (Trabalho original publicado em 1969)

Herbert, T. (1995). Observações para uma teoria geral das ideologias. RUA, 1(1), 6389. doi:10.20396/rua.v1i1.8638926

Krippendorf, J. (2009). Sociologia do turismo: para uma nova compreensão do lazer e das viagens ( $3^{\underline{a}}$ ed). São Paulo, SP: Aleph.

Lacan, J. (1992). O seminário: a transferência (Vol. 8). Rio de Janeiro, RJ: Jorge Zahar. (Trabalho original publicado em 1960-1961)

Lacan, J. (1996). O seminário: os quatro conceitos fundamentais da psicanálise (Vol. 11, $2^{\underline{a}}$ ed.). Rio de Janeiro, RJ: Jorge Zahar. (Trabalho original publicado em 1964)

Lacan, J. (1998). A instância da letra no inconsciente ou a razão desde Freud. In J. Lacan, Escritos (pp. 496533). Rio de Janeiro, RJ: Jorge Zahar.

Lacan, J. (1999). 0 familionário. In J. Lacan, O seminário: as formações do inconsciente (Vol. 5, pp. 1129). Rio de Janeiro, RJ: Jorge Zahar. (Trabalho original publicado em 1957-1958)

Laureano, P. S. (2015). Contribuições da psicanálise para a reconstrução da crítica à ideologia. Psicologia em Estudo, 20(3), 471482. doi:10.4025/psicolestud.v20i3.28184

Marx, K. (2017). Trabalho estranhado e propriedade privada. In K. Marx, Manuscritos econômico-filosóficos (pp. 7990). São Paulo, SP: Boitempo Editorial.

Moesch, M. M. (2000). A produção do saber turístico. São Paulo, SP: Contexto.

Pêcheux, M. (2014). Semântica e discurso: uma crítica à afirmação do óbvio (5ª ed.). Campinas, SP: Editora da Unicamp.

Pêcheux, M., \& Fuchs, C. (2014). A propósito da análise automática do discurso: atualização e perspectivas. In F. Gadet, \& T. Hak (Orgs.), Por uma análise automática do discurso: 
uma introdução à obra de Michel Pêcheux (5a ed., pp. 159250). Campinas, SP: Editora da Unicamp. (Trabalho original publicado em 1975)

Santos Filho, J. (2005). Ontologia do turismo: estudos de suas causas primeiras. Caxias do Sul, RS: Educs.

Žižek, S. (1992). Eles não sabem o que fazem: o sublime objeto da ideologia. Rio de Janeiro, RJ: Jorge Zahar.

Recebido em: 19/02/2017

Aprovado em: 20/11/2017

\section{CONTRIBUIÇÕES}

Maicon Gularte Moreira: definição do problema de pesquisa e objetivos, desenvolvimento da proposição teórica, realização da revisão bibliográfica e fundamentação teórica, escolha dos procedimentos metodológicos, revisão crítica do manuscrito, redação do manuscrito, adequação do manuscrito às normas da RTA.

Luciene Jung de Campos: definição do problema de pesquisa e objetivos, desenvolvimento da proposição teórica, escolha dos procedimentos metodológicos, revisão crítica do manuscrito. 